\title{
Mobile phone, social media usage, and perceptions of delivering a social media safer sex intervention for adolescents: results from two countries
}

This article was published in the following Dove Press journal:

Adolescent Health, Medicine and Therapeutics

\author{
Judith B Cornelius' \\ Charlene Whitaker-Brown' \\ Tamara Neely ${ }^{2}$ \\ Anna Kennedy' \\ Florence Okoro' \\ 'Department School of Nursing, \\ University of North Carolina at \\ Charlotte, Charlotte, NC, USA; \\ ${ }^{2}$ Director of Personal Care Services, \\ Homecare Carolinas at Charlotte. \\ Charlotte, NC, USA
}

Correspondence: Judith B Cornelius School of Nursing, 920I University City Blvd, CHHS 4I2B, Charlotte, NC 28223, USA

Tel + I 7046877978

Fax + I 7046876018

Email jbcornel@uncc.edu
Purpose: Rates of sexually transmitted infections among adolescents remain high in the United States and Botswana. Mobile phone density rates in Botswana exceed those of the United States. Yet, in both countries, safer sex information continues to be delivered primarily via face-to-face curricula such as Becoming a Responsible Teen and Living as a Safe Teen. While social media shows promise as a medium for delivering risk-reduction information to youth, few studies have been conducted in either country to assess its effectiveness. This study examines adolescents in both countries, their mobile phone and social media usage, and their perceptions of safer sex interventions delivered via social media.

Design and methods: Three focus groups were conducted with 28 adolescents 13-18 years of age who lived in the United States $(n=14)$ and Botswana $(n=14)$. Data analysis was ongoing, which informed the data collection process. After the first group, no additional revisions were made to the focus group protocol. An abridged method of analyzing the data was employed.

Results: Adolescents in all groups discussed peer pressure and connectedness with mobile phones and social media and had general knowledge of STIs and HIV. The adolescents agreed that adaptation of risk reduction interventions for mobile phone and social media delivery was warranted, and they shared ideas for adaptation.

Practice implications: Our findings provide a starting point for researchers interested in developing a social media intervention with global implications for sexual health promotion. Keywords: mobile phones, social media, adolescents, Botswana, United States

\section{Introduction}

Across the globe, more than one million individuals are infected daily with a sexually transmitted infection (STI) including HIV, and every year more than 357 million new infections are reported. ${ }^{1,2}$ These are particularly dangerous statistics for adolescents in which a large proposition of the newly STIs occur. ${ }^{2}$ Adolescence is a time for experimentation with drugs and alcohol, smoking, and risky sexual behaviors, ${ }^{3}$ and individuals ages 15 through 24 are contracting (STIs) at a much higher rate than other age groups.

Rates of STIs are high in both the United States and Botswana. In the United States youth and young adults (19-24 years of age) account for nearly half of the new infections each year. ${ }^{4}$ Data from the 2015 Youth Risk Behavior Surveillance Survey indicated that almost half of high school students in the United States (41\%), reported having had sexual intercourse. Some 30\% reported sexual intercourse during the previous three months, and of these, $43 \%$ did not use a condom 
the last time they had sex. Additionally, $15 \%$ of the youth said they have had sex with four or more partners, and only $10 \%$ reported ever having been tested for HIV. ${ }^{4}$

According to the Republic of Botswana Ministry of Basic Education, ${ }^{5}$ almost half of Botswana youth report limited knowledge of HIV, including modes of transmission. Results of the Second Botswana Youth Risk Behavioral and Biological Surveillance Survey of youth ages 10-19, indicated that $69.1 \%$ used a condom the first time they had sex, and almost half (48.9\%) reported having sex with more than one partner in the past year. More than half engaged in intergenerational sex (71\%); $13.4 \%$ had exchanged sex for money, drugs, or gifts; and 27\% reported STI symptoms. ${ }^{5}$

On the average adolescents in the United States experience sexual relations for the first time at about age $17,{ }^{6}$ while adolescents in Botswana report younger ages for sexual debut. ${ }^{7}$ Furthermore, among sexually active youth in Botswana, almost 33\% reported having sexual intercourse before the age of 13 . This is significant because HIV infection rates increase dramatically beginning at age 15, underscoring the need for education and prevention interventions. ${ }^{7,8}$ Such preventative measures could be delivered using technology such as mobile phones, which are in the hands of youth at all times.

\section{Mobile phone usage in both countries}

In the United States nearly $70 \%$ of all teens have access to a smartphone, and $30 \%$ have access to a basic cell phone. ${ }^{9}$ African-American teens are more likely than other ethnic groups to have a smartphone. Their usage is as high as $85 \%$, making them the primary drivers of teen social media. ${ }^{9}$

In Botswana, mobile phone density rates exceed those of industrialized countries including the United States the United Kingdom, and Germany. ${ }^{10}$ Across all villages, towns, and cities, so many individuals own mobile phones that the penetration is considered $100 \%{ }^{10,11}$ Thus, mobile phones may be one way of delivering health information to those most at risk with the adaptation of two safer sex interventions for adolescents-Becoming a Responsible Teen and Living as a Safe Teen.

\section{Becoming a responsible teen and living as a safe teen}

In the United States, Becoming a Responsible Teen (BART) is a face-to-face curriculum that has had success in reducing risky sexual behaviors with minority youth. BART is a community-based cognitive behavioral HIV risk-reduction curriculum designed for African-American adolescents, ages $14-18 .^{12}$ The curriculum consists of eight, 1.5- to 2-hour sessions that include interactive group discussions and role-playing. Participants are encouraged to practice safer-sex skills and to spread the word about HIV prevention to their friends. Unique features of this curriculum include adolescent involvement in all aspects of the curriculum and gender-specific groups facilitated by both male and female facilitators. The curriculum has been effective with both sexually experienced and abstinent youth in increasing HIV knowledge and sexual assertiveness. However, 12 months post intervention teens began showing risker sexual behaviors (J. St. Lawrence, personal communication, September 16, 2007).

Living as a Safer Teen (LAST) is an adapted version of BART. From a validation study with 65 teens in Botswana, BART was revised to include additional information on intergenerational sex and reproductive health. ${ }^{13}$ Similar to BART, LAST consists of eight sessions with interactive group discussions and role-playing. While the adaptations were found to be culturally relevant for Botswana youth, the curriculum continues to be delivered face to face to limited numbers of youth, who own mobile devices and have access to social media sites. Thus, both BART and LAST are practical curriculums for mobile delivery.

\section{Social media shows promise in the dissemination of safer-sex information}

Several programs have used mobile phone technology to provide safer sex, ${ }^{14,15}$ but few have used social media sites. ${ }^{16,17}$ In one study conducted in the United States, Bull et al. ${ }^{16}$ used social media messages to improve condom use among adolescents. Participants were randomly assigned to receive the Just/Us social media intervention or participate in the 18-24 News intervention group. Participants who received daily and weekly information about safer sex practices used condoms more often than those in the intervention group. One limitation of this study was that only short-term (two months) improvement with condom use was noted. After six months, there was virtually no difference in condom use between the two groups.

In Australia, a program known as The FaceSpace Project was implemented using social networking to promote safer sex in a targeted group of young people aged 16-29 years of age who attended a music festival. ${ }^{17}$ The program reached 900 to 1,332 participants via Facebook. 
The most effective way to reach a wide audience was through advertisements and photos on the Facebook page. $^{17}$

In Botswana, we only found one published study, which referred to social media usage in promoting safer sex behaviors. Batane ${ }^{18}$ conducted a one-group pretest/ posttest study with 117 university students to examine the effects of an online discussion forum on students' HIV risk behaviors. Findings indicated that there was a significant change in participants' behaviors in relation to knowing their HIV status, decreasing their number of sexual partners, and increasing condom use.

Healthcare providers want to disseminate information that will help youth avoid behaviors that put them at risk for contracting STIs. This includes knowledge about and access to condoms to prevent STI transmission, and knowledge about and access to clean needles so that those who inject drugs will not pass along HIV via shared needles. ${ }^{4}$ Better access to HIV testing and counseling, and stronger links to treatment services for those who test positive are also needed. ${ }^{4}$ One way of reaching this age group with more knowledge and greater access to care is with mobile health (mHealth) technology.

The purpose of this study was to examine mobile phone and social media usage among adolescents from two different countries and their perceptions on how we could adapt two safer sex interventions for delivery via mobile devices. We were also interested in examining similarities and differences between both groups of adolescents for development of a risk-reduction intervention delivered via social media.

\section{Methods}

Focus groups in the United States and Botswana were used to capture adolescents' mobile phone and social media usage, as well as their perceptions of risk-reduction interventions. Each of the three focus groups (two in the United States, one in Botswana) was comprised of participants who knew each other. This was intentional. In our previous research, we found focus groups to be an effective means of collecting data from minority participants, especially those who shared common experiences and habits $^{19,20}$

\section{Sample and setting}

Participants were recruited by the first author. Inclusion criteria were: 13-18 years of age, knowledgeable about smartphone usage and social networking sites, and able to provide assent and parental info. In the United States, two focus groups were conducted. The first group had five participants, and the second group had nine. Due to the inability of the researchers to meet with Botswana participants on more than one occasion, only one focus group was conducted with 14 participants, giving us a total sample size of 28 .

In the United States, participants were recruited from schools, churches, and community sites in the southeast region of the country. In Botswana, participants were recruited from community sites and schools, and had been previously involved in a larger grant involving the development of a face-to-face sexual risk-reduction intervention for Botswana youth. The focus group number in Botswana exceeded the prescribed number of 12 because we had to maximize our time in the country and use the resources that were available to us. ${ }^{21}$ We spent more time with participants in Botswana than in the United States so that data saturation could be reached. Two community sites were the settings for participants in the United States; the setting in Botswana was a university building.

\section{Procedure}

The first author's university Institutional Review Board and the Ministry of Health in Botswana approved the study. The participants provided the appropriate informed and written assent and consent forms in each country. Each focus group consisted of five or more participants. All focus group sessions were audio recorded and lasted approximately 1-2 hours. One focus group in the United States consisted of females only, while the other two groups were co-ed.

Upon arrival, the research team in both countries collected consent forms (participants assent and parental consent) and greeted participants arriving for the focus group sessions. Participants completed a demographic survey and provided information about their mobile phones and social networking. Next, they were allowed to interact informally for the first 20 minutes of the meeting. The first author then introduced the research team, discussed the purpose of the meeting, and explained use of the digital voice recorders in the center of the table. Next, the first author discussed the ground rules for participation, and participants agreed to these rules. They were required to use first names only, speak one at a time, and maintain group confidentiality. 
Table I Focus group questions

\begin{tabular}{|c|c|}
\hline Questions & Probes \\
\hline $\begin{array}{l}\text { What are your sources of HIV Knowledge? } \\
\text { - Tell me where and how often you hear information about HIV and STIs. }\end{array}$ & $\begin{array}{l}\text { Give me examples of information that you hear about with HIV and } \\
\text { STIs (information) }\end{array}$ \\
\hline $\begin{array}{l}\text { Why do so many young people still get infected with HIV and other STIs? } \\
\text { - What are risk factors related to young people getting infected with } \\
\text { HIV/STIs? } \\
\text { - Do you personally know anyone who has been infected with HIV or } \\
\text { another STI? } \\
\text { - What are barriers to getting care for HIV/STIs? }\end{array}$ & \\
\hline $\begin{array}{l}\text { According to research, young people are beginning to use social media } \\
\text { sites for health promotion information. What can you tell us about this? } \\
\text { - Why is social media so popular with young people today? } \\
\text { Can we use social media sites to deliver safer sex information? }\end{array}$ & $\begin{array}{l}\text { Can you provide names of social media sites that you use? } \\
\text { What are some reasons why social media sites should be a medium for } \\
\text { delivering safer sex information? (motivation) } \\
\text { What would young people like about the delivery process? How often } \\
\text { should safer sex information be delivered to social media sites? } \\
\text { Can we adapt face-to-face curricula, such as Becoming a Responsible } \\
\text { Teen or Living as a Safe Teen, for social media delivery? (behavioral skills) }\end{array}$ \\
\hline Anything else that you would like to share with us? & \\
\hline
\end{tabular}

\section{Data collection}

The interview questions were guided by the information, motivation, and behavioral (IMB) skill risk reduction model. ${ }^{22}$ The model proposes that information important for the practice of STI risk reduction behaviors and the motivation to make behavioral changes are fundamental determinants of STI risk reduction behaviors, which are amendable to change in behavioral interventions. The questions posed in the focus groups were intended to generate discussion about delivering a safer sex intervention to mobile devices and social media sites. Adolescents were asked about the mobile phones and social network sites they used (information), their receptivity to a riskreduction intervention (motivation), and ideas for development (behavioral skills). The list of specific focus group questions and probes are listed in Table 1.

The first author with post-doctoral training in HIV/ AIDS education moderated the focus groups in both countries. As the focus groups commenced, the first author wrote ideas from each session on a flip chart located in the front of the room. After completion of the focus groups, the first author presented a brief summary of the main ideas that had been discussed in each group. Participants were asked to verify if the information was correct, and to make additions and corrections as needed. In the United States participants received an incentive of $\$ 5.00$, and in Botswana participants received 60 pula
(\$6.25). All groups were provided a light snack before the sessions. Data saturation was reached after the third focus group.

The research team debriefed immediately after each focus group. After the first focus group, it was determined that no modifications to any of the questions were required since participants responded to each question in detail. The behavior of participants in each focus group was discussed. Participants in the all-female group were more reserved discussing safer sex information for social media intervention delivery when compared to the mixed-gender groups.

\section{Data analysis}

Data analysis was ongoing and informed the data collection process. After input from the first group session, however, no additional revisions were made to the focus group protocol. The first author, who had a thorough understanding of the study's purpose, then developed a condensed version of the audiotaped focus groups. This abridged method of analyzing the data ${ }^{23}$ focused on relevant content to address similarities and differences only. The team then discussed themes supported by remarks from participants as exemplars of the data.

Despite variation in focus group composition, data from the three groups were fairly consistent. Adolescents in all groups discussed peer pressure and connectedness 
with social media. In the first focus group, the discussion centered on peer relationships, mobile phones, and social media. In the second group, participants talked about school and peer relationships, mobile phones, and social media. In the third group, participants in Botswana discussed acceptance of social media for delivery of health information and peer relationships. The probable reason for emphasis on this topic was their recent involvement in developing a sexual risk-reduction intervention for youth.

\section{Results}

\section{Demographic characteristics and mobile phone usage}

Table 2 provides the results of chi-square analysis on the participants' demographic characteristics. In the United States all participants identified as African American $(\mathrm{n}=14)$ in Botswana all participants identified as African $(n=14)$. The sample was predominantly female and 16 years of age (SD 1.2). Participants in the United States when compared to those in Botswana were younger $\mathrm{x}^{2}(1, \mathrm{~N}=28=3.30 p<0.05)$ in lower grades in school $\mathrm{x}^{2}(2$, $\mathrm{N}=28=3.2 p<0.05)$ and lived with both parents $\mathrm{x}^{2}(3$, $\mathrm{N}=28=3.8 p<0.05)$. All of the participants had mobile phones and a social media account. All but one youth in the United States owned a smartphone, while $64 \%$ of the Botswana youth owned smartphones $(p<0.05)$. The main type of smartphone used in the United States was an iPhone, while in Botswana it was the Blackberry. Participants in both groups had similar background characteristics with people they follow and the people who follow them. Study participants in both countries indicated that they follow up to 300 individuals on social media and that the same number of individuals follows them (see Table 2).

\section{HIV knowledge sources}

In each focus group session, the first author began by asking what do you know about HIV, and where do you get your information? Participants from both countries had similar responses. Both groups said their primary source of knowledge about HIV (what it is, facts and myths, and modes of transmission) came from school. Participants from the United States said they also gathered information from television and social media, citing popular television shows such as Maury Povich, Jerry Springer, and The Steve Wilkos Show. Tyler Perry's movie "Temptation: Confessions of a Marriage Counselor" was also cited as a source of HIV information. One US participant summed up all the sources of HIV information: "From people in our school who are HIV positive, TV, media, and family members." When asked how often they hear about STIs and HIV one participant said, "A lot. Because we learn about it at school."

Participants from Botswana indicated that television and social media were sources of HIV information, but school was the primary source. One participant in Botswana said, "We do not talk about HIV prevention at home. We talk about it in school. Staying in school keeps me up to date with facts about HIV and AIDS."

\section{Reasons why high rates of infection exist}

Participants were asked why rates of HIV infection remain high. Youth in both countries indicated that they know about HIV and STIs, but that they do not believe that it can happen to them, that it is an adult disease. They feel invincible. Participants from the United States reported that infection rates were high because they don't listen to the warnings and use protection. Many of the participants said they personally know of someone who has been infected with an STI. One of them put it this way,

Adolescence is a period of risk-taking and with significant peer pressure. Because we are followers, you see one person having sex and then everybody is doing it. No one is thinking individually, so if everyone else is doing it so you just do it too.

Lack of testing was another reason cited as to why infection rates remain high. According to one participant from the United States, "Because they aren't getting tested, they are just going around sleeping with people and getting infected." Youth also suggested that overexposure to youth having sexual relations, low selfesteem, and insecurity were reasons why infection rates remain high.

Similarly, one participant in Botswana said, "Many young girls and boys have intergenerational sex with older men or women to get money or material things. There is not a discussion about safe sex among sexual partners. If you do, then the person may stop giving you things." Another said, "I know many youths who drink alcohol then engage in risky sexual behaviors. It is not safe and they know it, but they do it anyway. I really do not know why. This puts them at risk or they become infected with HIV or an STI." 
Table 2 Demographic characteristics, cell phone, and social media usage

\begin{tabular}{|c|c|c|c|c|}
\hline Variable & $\begin{array}{l}\text { Botswana } \\
(n=14)\end{array}$ & $\%$ & $\begin{array}{l}\text { United } \\
\text { States } \\
(n=\mid 4)\end{array}$ & $\% x^{2}$ \\
\hline \multicolumn{5}{|l|}{ Age (years) } \\
\hline $13-16$ & 3 & 21 & II & $79 *$ \\
\hline $17-20$ & 7 & 50 & 1 & $7 \mathrm{NS}$ \\
\hline Missing & 4 & 29 & 2 & 14 \\
\hline \multicolumn{5}{|l|}{ Gender } \\
\hline Male & 5 & 36 & 3 & $21 \mathrm{NS}$ \\
\hline Female & 9 & 64 & II & 79 NS \\
\hline Missing & 0 & 0 & 0 & 0 \\
\hline \multicolumn{5}{|l|}{ Grade } \\
\hline $1-3$ & 4 & 29 & 0 & $0^{*}$ \\
\hline $5-7$ & 5 & 36 & 3 & $21 \mathrm{NS}$ \\
\hline 8 and over & I & 7 & II & $79 *$ \\
\hline Missing & 4 & 29 & 0 & 0 \\
\hline \multicolumn{5}{|l|}{ Live with } \\
\hline Both Parents & 6 & 43 & II & $79 *$ \\
\hline Mom only & 5 & 36 & 2 & $14^{*}$ \\
\hline Father only & I & 7 & 0 & $0 \mathrm{NS}$ \\
\hline Other & 2 & 14 & 0 & 0 NS \\
\hline Missing & 0 & 0 & 1 & 7 \\
\hline \multicolumn{5}{|c|}{ Owns a smartphone } \\
\hline Yes & 9 & 64 & 13 & $93^{*}$ \\
\hline No & 4 & 29 & I & $7 \mathrm{NS}$ \\
\hline Missing & I & 7 & 0 & 0 \\
\hline \multicolumn{5}{|c|}{ Social media account } \\
\hline Yes & 12 & 86 & 14 & $100 \mathrm{NS}$ \\
\hline No & 2 & 14 & 0 & 0 \\
\hline \multicolumn{5}{|c|}{ People you follow } \\
\hline $0-300$ & 9 & 64 & 11 & 79 NS \\
\hline $30 I-600$ & I & 7 & 2 & 14 NS \\
\hline $60 I-900$ & 0 & 0 & 0 & ONS \\
\hline $901-1200$ & 1 & 7 & 0 & 0 NS \\
\hline Over I20I & 2 & 14 & 1 & $7 \mathrm{NS}$ \\
\hline Missing & 1 & 7 & 0 & 0 \\
\hline \multicolumn{5}{|c|}{ People who follow you } \\
\hline $0-300$ & 8 & 57 & 10 & $71 \mathrm{NS}$ \\
\hline $30 I-600$ & 2 & 14 & 3 & $21 \mathrm{NS}$ \\
\hline $60 I-900$ & 0 & 0 & 0 & 0 NS \\
\hline $901-1200$ & I & 7 & 0 & 0 NS \\
\hline Over 1201 & 2 & 14 & I & $7 \mathrm{NS}$ \\
\hline Missing & I & 7 & 0 & 0 \\
\hline
\end{tabular}

Note: ${ }^{*} p<0.05$

Abbreviation: NS, not significant.

\section{Social media sites}

The first author asked participants about preferred social media sites. In the United States participants said they used Facebook, Twitter, and Instagram. In Botswana, participants reported their favorites as Facebook, WhatsApp, and Viper. They were not familiar with Twitter and Instagram. While the social media sites differed, youth in both countries used more than one site with Facebook being the primary site used in both countries.

Participants from the United States indicated that while they used Facebook and Twitter, they were losing interest and going to other social media sites, such as Instagram. One participant said, on Facebook "everybody says the same thing over and over and over." Another added, "At first when I got on, it was cool. You knew all of the drama, but now it's kind of boring." Another reason participants said that they were switching to Instagram in the United States is because their parents are on Facebook, but not Instagram. This suggests that if parents join social media sites, it may have an impact on the content that teens post. "If you don't want parents to be on Facebook, then there is something you want to hide," one participant said. "You are doing something you are not supposed to be doing." However, some participants said they did not mind that their parents were on the same social media sites. One said, "I think parents should start getting on Twitter as well because their kids are getting on Twitter."

In Botswana, Facebook remained popular, but messaging apps, WhatsApp and Blackberry messenger, were gaining popularity. Differences between the phones used in the two countries could explain why messaging apps were popular in Botswana. One youth said, “...Not all of us really have trendy phones..." In Botswana, it was common for phone plans to charge extra for text messaging like phone plans in the US years ago. By using messaging apps, these participants got around paying for text messages.

\section{Can social media sites be used to deliver safer sex information?}

When asked about using a social media sites to deliver safer sex information, youth in both countries unanimously agreed that it was a great idea. One reason they gave was because teens are on social media sites daily. They recommended that the topics be trendy and that captions catchy and able to grab somebody's attention. One. participant from the United States said, "If you guys (researchers) make those messages trendy enough, it can go far." 
When asked how often they would like to receive a message or a post, responses varied between the groups. Youth in the United States suggested one to three times per day. One suggested choosing a certain day to post, like "STD Saturday." Others suggested posting or sending messages during school hours. When asked if youth would get in trouble for using their phones in school, participants in the United States agreed that they would not. One added, "We won't get in trouble if it's about awareness, plus a lot of sexual activity happens when we are in school."

In Botswana, responses varied on when adolescents would like to receive messages. Participants suggested twice a day to twice a week. When asked if they preferred the morning or the evening, responses varied from 8-9 am to 5-6 pm. A Botswana youth added, "It should be different messages every day. In the morning, there should be a different message from the one in the evening." In contrast to participants in the United States, Botswana youth did not want to receive messages during school hours. The youth reported that their phones usually remain silent during school hours, and they would get in trouble for using their phones.

Participants from Botswana were more focused on whether the messages or pictures seemed real to them. When shown pictures and videos with safer sex messages from BART and its adapted version of LAST, the youth said that the actresses, actors, scenes, and dialogues did not seem realistic to them. When asked what would make these more real to them, some suggested adding informative messages below the pictures. The youth were shown a picture of a boy and girl hugging, when asked what would make this picture seem real one youth said, "I would add a caption saying that HIV is not transmitted through hugging." Youth in the United States wanted messages to be short and to the point, but also attention grabbing and entertaining. Both groups recommended varying the message format and designing the information to be engaging.

\section{Discussion}

Overall, this study sought to examine cell phone and social media usage, and the possibility of delivering safer-sex interventions via social media to adolescents in two different countries. We found similarities exist among what youth want in risk-reduction messages delivered via social media sites. Differences existed in the types of cell phones and social media sites that were being used. Since data collection, our research shows that more youth in Botswana are now using iPhones and Twitter. The Blackberry has become obsolete just like in the United States.

The relationship between the users and technology was similar in both countries. The need to connect with family and friends was noted. However, initial adoption of mobile technology varied greatly. Youth in the United States are acquiring mobile phones at younger ages, 9-11 years, while youth in Botswana are older (15 years plus) because many have to work to purchase their own phones. ${ }^{9,10}$ Mobile phone features, such as texting, are most commonly used by youth in both countries followed by taking pictures and videos. ${ }^{23}$ These features help youth feel connected to each other, ${ }^{10}$ and show promise in the development of an interactive mHealth safer sex intervention.

Consistent with previous research, the youth used Facebook more frequently than any other social media site, although they used more than one site. ${ }^{9}$ Social media sites are exploding as youth find features on relatively new sites, such as Snapchat and Tumblr, appealing. While youth in Botswana were not using Instagram at the time of this study, it is now a top social media site in that country along with Mivasocial, Tumblr, and Pinterest.

Youth in both countries agreed that using social media sites to deliver safer-sex information was an excellent idea. Studies using this method of delivering health information in Botswana are long overdue and they are limited in the United States. There were similarities in the intervention content and design that participants in each country wanted. For example, knowledge about substance use, HIV/AIDS knowledge and facts, and safe sex behaviors were topics of interest in both countries, but the issue of intergenerational sex is not. The trading of sex for money and gifts is more prevalent in Botswana than in the United States. Thus, this topic might be emphasized in risk-reduction intervention for youth in Botswana, but not in the United States.

The potential of using mHealth technology to influence behavior change is well documented in the literature. ${ }^{16,19,24,25}$ Similar to research using text messages to deliver safer sex information to study participants' mobile phones, the messages should be varied to attract the attention of youth. ${ }^{19,20}$ For example, a social media message with a video could be sent one day, and a picture with a message could be sent another day. Youth in this study were receptive to the 
idea of using social media for the delivery of safer sex information. And why not? This is how they live. This is how they learn.

As social media sites have emerged, networks of like individuals have formed. These networks are often private and protected from those who are not allowed to join. Social media sites build relationships and increases visibility. Individuals can connect at anytime, a disadvantage of face-to-face interventions. In one article, $90 \%$ of respondents from the millennial network trusted healthcare information shared by others on social networks ${ }^{26}$ and $60 \%$ were most likely to trust social media posts by health care providers. $^{27}$ In another study, participants identified the ease of use, support on demand, regardless of location, as advantages of internet delivered interventions. ${ }^{12}$ The social media delivery format can go into depth because someone is always connected and responding. The capability of delivering content using multimedia formats such as videos, pictures, and messaging exceeds that of face-to-face platforms. Hence these benefits are advantageous in disseminating risk reduction information to youth when compared to face-to face interventions that are limited to specific times, locations, make up sessions, and lack of support on demand.

\section{Limitations}

Our study has limitations. First, the research was exploratory, and findings may not be generalizable. The focus group methodology allowed us to examine the perceptions of the targeted group regarding their mobile phone and social media usage and their ideas about a socialmedia-based intervention. Second, our study included a small purposive sample of adolescents, some of whom had participated in a face-to-face safer-sex course. Their responses might differ from those without that experience.

\section{Conclusion}

The experiences of the adolescents who participated in this project highlight the importance of considering the use of social media to meet the health promotion needs of this age group. More similarities than differences existed in the mobile phone and social media usage of youth in both countries. Youth in both countries felt the need to remain connected with family and friends, and gave that as a reason for owning a mobile phone and being on social media sites. Their perceptions of receiving a safer-sex intervention via social media were positive and informative. This finding is important as we identify ways of reaching at-risk youth with health promotion information. This study has reshaped our understanding as to how we can use technology to disseminate sexual health information globally when designing safer-sex interventions. As we begin to focus on in depth development of a social media risk reduction intervention we will need to consider the delivery format, dosage, cost for delivery, and internet access in both countries.

\section{Acknowledgments}

We thank Michael Chiseni (University of North Carolina at Charlotte), William Thabana (University of North Carolina at Charlotte), Josephine Appiah (University of North Carolina at Charlotte) and Khalia Braswell (University of North Carolina at Charlotte) for their support in reviewing our data and providing cultural insight. The authors also wish to acknowledge the assistance of Drs Janet St. Lawrence, Esther Seloilwe, and Mabel Magowe of Botswana in data collection, focus-group moderation, and cultural relevance.

\section{Disclosure}

The authors report no potential conflicts of interest with respect to the research, authorship, and/or publication of this article.

\section{References}

1. World Health Organization. Sexually Transmitted Infections. Published 2015. Available from: http://www.who.int/news-room/fact-sheets/detail/ sexually-transmitted-infections-sti. Accessed September 18, 2018.

2. Centers for Disease Control and Prevention. 2017. STD Facts. Reviewed October 2018. Available from: https://www.cdc.gov/std/ default.htm. Accessed October 8, 2018.

3. Office of Adolescent Health. Adolescent sexual behavior. 2017. Available from: https://www.hhs.gov/ash/oah/resources-and-publications/info/par ents/just-facts/adolescent-sex.html. Accessed October 8, 2018.

4. Centers for Disease Control and Prevention. Sexual risk behaviors: HIV, STD, \& teen pregnancy prevention. 2016. Available from: https:// www.cdc.gov/healthyyouth.gov/sexualbehaviors/index.htm. Accessed October 8, 2018.

5. Republic of Botswana Ministry of Basic Education. Second Botswana youth risk behavioral and biological surveillance survey report. 2016. Available from: http://www.gov.bw/Global/MoE/Schools/FINAL\% 20REPORT.pdf. Assessed September 18, 2018.

6. Guttmacher Institute. Adolescent sexual and reproductive health in the United States. 2017. Available from: https://www.guttma cher.org/fact-sheet/american-teens-sexual-and-reproductive-health. Accessed September 18, 2018.

7. Botswana 2013 Global AIDS Response Report. Modes of transmission. 2014. Available from: http://www.unaids.org/sites/default/files/country/docu ments/BWA_narrative_report_2014.pdf. Accessed September 18, 2018.

8. Botswana AIDS Impact Survey Summary. 2014. Available from: http:// www.cso.gov.bw/index.php/summary-statistics/18-demography/103botswana\%20aids-impact-survey-summary-2014. Accessed September $18,2018$. 
9. Lenhart A. Teens, Social Media, and Technology Overview. Pew Research Center; 2015. Available from: http://www.pewinternet. org/2015/04/09/introduction-teens-tech/. Accessed September 18, 2018 .

10. William L. Influencing factors to mobile phone adoption among urban youth in Botswana. J Media Commun. 2016;8(1):8-14. Available from: http://www.academicjournals.org/journal/JMCS/arti cle-full-text-pdf/F2869A956898

11. Lesitaokana W. Young people and mobile phone technology in Botswana. In: Cahill W, editor. Handbook of Child and Youth Studies. Singapore: Springer; 2015:801-813. doi:10.1007/978-981-4451-15-4_30

12. St. Lawrence JS, Brasfield TL, Jefferson KW, Alleyne E, O’Bannon RE, Shirley A. Cognitive-behavioral intervention to reduce African American adolescents' risk for HIV infection. J Consult Clin Psy. 1995;63(2):221-237. doi:10.1037/0022-006X.63.2.221

13. St. Lawrence J, Seloilwe E, Magowe M, et al. Cross-cultural adaptation of an adolescent HIV prevention program: social validation of social contexts and behavior among Botswana adolescents. AIDS Educ Prev. 2013;25(4):269-286. doi:10/152.aeap.2013.25.4.269

14. Cornelius J, Appiah J. Using mobile technology to promote safe sex and sexual health in adolescents: current practices and future recommendations. Adol Health Med Therp. 2016;7:43-57.

15. Kachur R, Mesnick J, Liddon N, et al. Adolescents, Technology and Reducing Risk for HIV, STDs and Pregnancy. Atlanta (GA): Centers for Disease Control and Prevention; 2015.

16. Bull S, Levine D, Black S, Schmiege SJ, Santelli J. Social media delivered sexual health intervention. Am J Prev Med. 2012;43 (5):467-474. doi:10.1016/j.amepre.2012.07.022

17. Nguyen P, Gold J, Pedrana A, et al. Sexual health promotion on social networking sites: a process evaluation of the FaceSpace Project. J Adoles Health. 2013;53(1):98-104. doi:10.1016/j.jadohealth2013.02.007
18. Batane T. Social media in promoting HIV/AIDs prevention behavior among young people in Botswana. Social Med Mob Tech Healthcare. 2014;264-279. doi:10.4018/978-1-4666-6150-9-ch015

19. Cornelius J, St. Lawrence J, Howard J, et al. Adolescents' perceptions of a mobile phone text messaging-enhanced intervention and development of a mobile phone-based HIV prevention intervention. J Spec Pediatr Nur. 2012;17(1):61-69. doi:10.11/j.1744-6155.2011.00308.x

20. Cornelius J, St. Lawrence J. Receptivity of African American adolescents to an HIV-prevention curriculum enhanced by text messaging. J Spec Pediatc Nur. 2009;14(2):123-131. doi:10.111/j.17446155.2009.00185x

21. Morgan D. The Focus Group Guidebook. Thousand Oaks, CA: Sage; 1998.

22. Fisher J, Fisher W. Changing AIDS risk-behavior. Psych Bulletin. 1992;111(3):455-474. doi:10.1037/0033-2909.111.3.455

23. Krueger R. Developing Questions for Focus Groups. Thousand Oaks (CA): Sage; 1998.

24. Pew Research Center. Cell phones in Africa: Communication Lifeline. 2017. Available from: http:/www.pewglobal.org/2015/04/ 15/cell-phones-in-africa-communication-lifeline/. Accessed September 18, 2018.

25. Cole-Lewis H, Kershaw T. Text messaging as a tool for behavior change in disease prevention and management. Epid Rev. 2010;32 (1):56-69. doi:10.1093/epirev/mxq004

26. Search Engine Watch. $33 \%$ of US consumers use social media for health care info [survey]. 2019. Available from: https://searchenginewatch.com/ sew/news/2169462/-consumers-social-media-health-care-info-survey. Accessed September 18, 2018.

27. Mueller A. Infographic: everything you need to know about docs and social media. Health Care Comm News. Available from: https://www. healthcarecommunication.com/Main/Articles/8290.aspx. Accessed September 18, 2018.
Adolescent Health, Medicine and Therapeutics

\section{Publish your work in this journal}

Adolescent Health, Medicine and Therapeutics is an international, peer-reviewed, open access journal focusing on health, pathology, and treatment issues specific to the adolescent age group. All aspects of health maintenance, preventative measures and disease treatmen interventions are addressed within the journal and practitioners from

\section{Dovepress}

all disciplines are invited to submit their work as well as healthcare researchers and patient support groups. The manuscript management system is completely online and includes a very quick and fair peerreview system. Visit http://www.dovepress.com/testimonials.php to read real quotes from published authors. 